It is the second case of the kind which has come under my observation. Subsequent history : Disappearance of symptoms; five weeks after operation there is still a small discharging sinus.

Case 5.-The last case which I present to you is one of great interest. This man 40 years of age has been complaining for some weeks of rheumatic pains. He comes to us with this great swelling in and around the left knee joint; this swelling extends half way up the thigh and half way down the leg; the surface is covered with patches of ecchymosis. Examining the man's body I find multiple patches of ecchymosis on his arms and other thigh. $\mathrm{He}$ tells me that these ecchymosed patches occur from the slightest injury; that whenever he cuts himself he bleeds very profusely; that once he had a tooth extracted with alarming hemorrhage following. He does not know that any member of his family is similarly affected. This is evidently a case of hemophilia. The joint is a hemophilic knee joint. The treatment we shall advise is rest, compression with a flannel bandage, careful avoidance in the future of injury. These cases sometimes after repeated attacks have ankylosis result. The subsequent history : Patient was seen at end of two weeks; had improved greatly. He then passed out of observation.

\section{GRAFTING FOR THE CURE OF EPITHELIOMA.}

$$
\text { BY P. D. KEYSER, M.D. }
$$$$
\text { PHILADELPHIA. }
$$

The removal of epithelioma by the knife or caustic has so far, been seldom, if ever a permanent cure, and as this disease appears mostly on the face especially near the eyes or mouth and in persons advancing in years, it becomes a source of distress and pain as well as a blemish, and in the removal by knife or caustic often a very defective scar is left with contractions of the lids and mouth which interfere with the natural and proper use of those parts. Transplanting from neighboring parts creates a greater defect, really defacing two parts; that where the epithelioma was, and that from which the piece of skin transplanted was taken. The drawing of the edges of the wound together where the disease is cut out causes very much contraction, interfering with the opening of the eyes or mouth. Even after such an operation, return of the disease occurs in a very short time, no doubt caused in very many cases by the not complete and thorough removal of the growth in the first place.

Knowing now from the latest studies that epithelioma is entirely a local disease of bacteriologic origin its thorough removal is necessary to insure a cure; and in doing this the gap in the skin must be filled up in some way, and lately grafting has been suggested instead of transplanting, so as to leave as little defect as possible; it is also claimed that the placing of healthy integument in the wound creates a healthy condition of all the surrounding parts and removes the tendency to a return of the disease.

To test the efficacy of this procedure I have during the past winter operated upon a very interesting case which is presented in this paper.

Mr. M., age 54, of Virginia, has been suffering with a slow growing epithelioma in the inner canthus of the right eye for over twelve years. It commenced in a small spot on the lower lid just below the line of the canaliculus. It gradually grew up towards the canthus, when four years ago he underwent an operation for its removal by the electric cautery. It was reported that it had all been removed; the wound, however, never healed properly, but instead, it seemed as if the growth was increased in vitality and started to grow rapidly, presenting the appearance of Fig. 1 as first seen by me.

Under an anesthetic I removed the disease completely with knife and scissors, and after stopping the hemorrhage, (which is always very free in such cases) by application of hot water sponges, I shaved a very thin graft from his upper arm, in size and shape so as to fit in freely and exactly the gap made by the removal of the diseased part.

Everything was done under thorough antiseptic preparation and influences. The solution of bichlorid of mercury being used 1 to 4000 on the eye and arm. The graft as soon as removed from the arm being

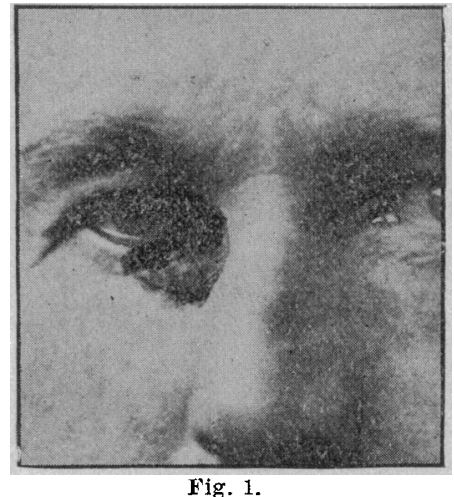

placed in a warm saturated solution of salt water, and then carefully transferred and fitted to the wound. The wound was covered with a piece of antiseptic oiled silk, over which were carefully laid and bound moist hot sublimate cloths and antiseptic cotton wool. As soon as the eye was bound up, applications of cloths steeped in hot water were constantly laid over the whole for an hour, and renewed after two hours. This being done to start up vitality in and around the graft. The latter applications I have always found a great adjuvant in the adherency and life of the graft in all such operations. After the

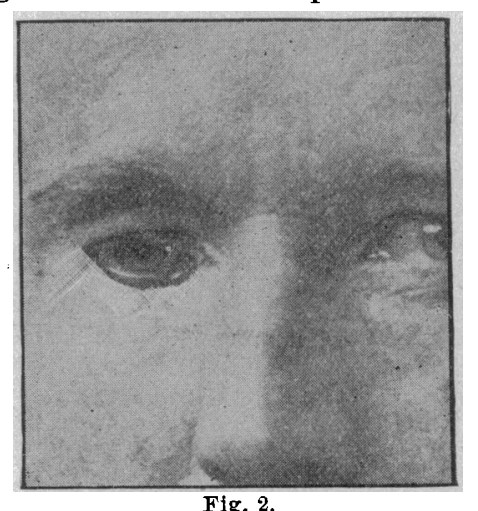

Fig. 2.

second day the oiled silk was removed and dry dressing applied for five days, after which the air was permitted to reach the graft through a thin drylgauze cloth laid over the part.

This operation has now been six months and the eye is as perfect as can be, there being no irritation or gign of the return of the growth.

Fig. 1. shows the case as first presented and Fig. 2 one month after the operation and as it is at present.

The success of this case recommends without doubt, this method of treatment of all cases of epithelioma on any part of the body if taken in time and before too large or deep and attacking vital parts. 